\title{
The erosion performance of particle reinforced metal matrix composite coatings produced by co-deposition cold gas dynamic spraying
}

\author{
Tom Peat ${ }^{a}$, Alexander Galloway ${ }^{a}$, Athanasios Toumpis ${ }^{a}$, Philip McNutt ${ }^{b}$, Naveed lqbal ${ }^{c}$

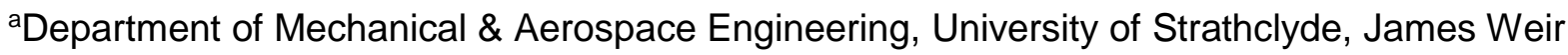 \\ Building, 75 Montrose Street, Glasgow G1 1XJ, United Kingdom \\ bTWI, Granta Park, Cambridge, CB21 6AL, United Kingdom \\ 'TWI, Wallis Way, Catcliff, Rotherham, S60 5TZ, United Kingdom
}

\begin{abstract}
This work reports on the erosion performance of three particle reinforced metal matrix composite coatings, co-deposited with an aluminium binder via cold-gas dynamic spraying. The deposition of ceramic particles is difficult to achieve with typical cold spray techniques due to the absence of particle deformation. This issue has been overcome in the present study by simultaneously spraying the reinforcing particles with a ductile metallic binder which has led to an increased level of ceramic/cermet particles deposited on the substrate with thick $(>400 \mu \mathrm{m})$ coatings produced. The aim of this investigation was to evaluate the erosion performance of the co-deposited coatings within a slurry environment. The study also incorporated standard metallographic characterisation techniques to evaluate the distribution of reinforcing particles within the aluminium matrix. All coatings exhibited poorer erosion performance than the uncoated material, both in terms of volume loss and mass loss. The $\mathrm{Al}_{2} \mathrm{O}_{3}$ reinforced coating sustained the greatest amount of damage following exposure to the slurry and recorded the greatest volume loss (approx. $2.8 \mathrm{~mm}^{3}$ ) out of all of the examined coatings. Despite the poor erosion performance, the WC-CoCr reinforced coating demonstrated a considerable hardness increase over the asreceived AA5083 (approx. 400\%) and also exhibited the smallest free space length between adjacent particles. The findings of this study reveal that the removal of the AA5083 matrix by the impinging silicon carbide particles acts as the primary wear mechanism leading to the degradation of the coating. Analysis of the wear scar has demonstrated that the damage to the soft matrix alloy takes the form of ploughing and scoring which subsequently exposes carbide/oxide particles to the impinging slurry.
\end{abstract}




\section{Keywords}

Cold spray; Erosion; Metal matrix composite; Solid liquid impingement; Cermet; Aluminium

\section{Introduction}

Cold gas dynamic spraying (cold spray) is a low temperature surface engineering process that is used to deposit coatings on a variety of substrate materials through the acceleration and impingement of feedstock powder particles. The technology was first developed in the early 1980's [1] and has been the subject of extensive research, particularly in the area of metal matrix composite (MMC) coatings [2-9]. Cold spray makes use of a de-Laval [1] nozzle to accelerate powder feedstock material to supersonic velocities. High temperature spraying technologies such as high velocity oxy-fuel (HVOF) [10] or plasma spray [10] expose feedstock powder to melting temperatures, hence causing a change to the constituent phases of the deposited coating. However, the temperature of cold sprayed powders never approaches their melting point [11]. As the particles impinge on the surface, the high kinetic energies cause them to plastically deform; this is commonly referred to as splat formation $[12,13]$. Multiple adjoining splats bond together to form the coating layer [12].

The primary advantage of cold spray over high temperature spraying processes is the ability to retain the constituent phases of the feedstock powder [11,14]. By maintaining the particle temperature below the solidus, any undesirable phase transformations within the powder particles are avoided. Coatings produced in this manner exhibit a work hardened structure [1] with existing research reporting the presence of compressive residual stresses $[15,16]$ which lead to enhanced fatigue performance [17]. The temperatures present during cold spray allow the technique to be applied to materials with a low melting point such as aluminium or magnesium. This is of particular interest to the automotive and aerospace industries which strive to optimise components for minimal weight whilst maintaining strength and wear performance $[18,19]$.

The use of cold spray to deposit wear resistant coatings has inherent complexities due to the difficulties in building up a sufficient coating thickness with wear resistant particles [20]. Deposition of wear resistant coatings, particularly ceramic materials such as tungsten carbide or alumina is difficult to achieve due to the limited deformability of ceramic particles while in a solid state. High temperature thermal spraying techniques overcome this problem by heating the particles above the solidus [21]. The negligible deformation of impinging carbide particles has been shown to produce a grit blasting effect on the surface of the substrate material [22].

By optimising the spraying parameters, Couto et al. [23] were able to deposit a coating comprising tungsten carbide particles. However, the limited deformation of the cermet upon 
contact with the substrate restricted the build up of thick $(>100 \mu \mathrm{m})$ coating layers. The addition of a ductile metallic binder has been shown to enable the deposition of ceramic particles [23], with the binder typically being added to the sprayed powder in one of two ways. One method involves the agglomerating-sintering of metallic binder and carbide [23]. Typical examples of this process include the production of WC-CoCr and $\mathrm{Cr}_{3} \mathrm{C}_{2}-\mathrm{NiCr}$ powders [24]. This is limited to certain material combinations and requires that powders are manufactured in advance of the spray process. Incorporation of a metallic binder can also be achieved by mixing powders to the required ratio prior to spraying. Irissou et al. [9] employed such a technique to deposit pre-mixed $\mathrm{Al}+\mathrm{Al}_{2} \mathrm{O}_{3}$ on steel. This approach is comparably less complicated than agglomeration and is applicable to a greater range of material combinations. However, varying densities of powder particles can cause settling within the powder feeder resulting in inconsistent quantities of ceramic and binder supplied to the nozzle. In contrast, co-deposition is seen as a potential technique to overcome the inherent difficulties in depositing ceramic powders using cold spray [23], by spraying a binding alloy on the substrate alongside the ceramic particles. It should be noted that only the ductile metallic alloy undergoes deformation during the cold spraying of cermet powders.

Examination of MMC coatings has gathered substantial interest in recent years due to the improvements to mechanical properties with the addition of certain reinforcing particles [25-31]. These improved properties derive from dispersion (Orowan) strengthening [32] in which dislocations in the matrix are pinned by the dispersed particles. Cold spraying adds further strengthening in the form of work hardening [33] and grain refinement of the binder material [3436]. Severe plastic deformation produces a work hardened structure as the grains in the powder particles become elongated following impact. Grain refinement is common in particles that suffer particularly extensive plastic deformation such as those that directly impact the substrate surface. The substantial pressures upon impact cause recrystallization of the plastically deformed grains. Evidence of grain refinement has previously been reported for $\mathrm{Zn}, \mathrm{Cu}$ and $\mathrm{Ti}$ cold sprayed powders [35,37,38].

The influence of each of these mechanisms on the strength of the MMC is dependent on the distribution and structure of reinforcing particles [32,33]. A study by Luo et al. [33] investigated the contribution of the various strengthening mechanisms to the measured hardness increase of a cold spray deposited pcBN/NiCrAl composite coating. The authors [33] characterised the dispersal of particles within the coating and calculated the theoretical hardness based on this distribution and the volume fraction of reinforcements. The experimentally measured hardness values closely reflected the calculated ones. Work hardening from the plastic deformation of deposited particles was identified as the most significant strengthening mechanism followed by 
matrix grain refinement and dispersion strengthening [33]. The level of dispersion strengthening is directly linked to the size and distribution of reinforcing particles within the matrix; a decrease in sub-micron reinforcement particle size is linked to increased strengthening. Redsten et al. [39] found that reducing the reinforcement particle size to below $0.1 \mu \mathrm{m}$ resulted in dispersion strengthening becoming the dominant strengthening mechanism within the MMC [39].

A number of studies $[33,40,41]$ relate the hardness of MMCs to the dispersal of reinforcing particles in the matrix, with homogenous distribution of fine particles generating superior mechanical properties [42]. The erosion performance of MMCs has also been examined by several authors, with the findings highlighting a reduction in the erosion rate of alloys with the addition of particulate reinforcements $[43,26,44]$. However, the existing research does not extend to the examination of cold sprayed MMCs co-deposited with a metallic binder alloy under a solid liquid impingement testing regime.

In the present study, the micro-hardness and metallographic analysis of three MMC coatings produced by co-deposition cold spraying, prior to erosion testing, established the distribution and quantity of cermet within the aluminium matrix. The erosion performance of the MMC coatings was evaluated under flowing conditions using solid liquid impingement test apparatus. The material loss from the three particle reinforced MMC coatings was measured at $90^{\circ}$ angle of attack, with the recorded data compared to the material loss from as-received AA5083. Post-erosion analysis of the wear scar region determined the mechanisms causing breakdown of the MMC coatings. This body of research has developed an enhanced understanding of the microstructure and erosion performance of co-deposited cold sprayed MMC coatings in flowing slurry conditions.

\section{Methodology}

\subsection{Materials}

The erosion performance of cold spray deposited tungsten carbide (WC-CoCr), chromium carbide $\left(\mathrm{Cr}_{3} \mathrm{C}_{2}-\mathrm{NiCr}\right)$ and aluminium oxide $\left(\mathrm{Al}_{2} \mathrm{O}_{3}\right)$ reinforced $\mathrm{MMC}$ coatings has been evaluated under solid liquid impingement flowing conditions. AA5083 was selected as the substrate material due to its extensive use within the automotive and aerospace sectors [45]. While this material is appropriate for use in these sectors, enhanced tribological properties are required to extend operational life and reduce maintenance costs associated with components [46]. The chemical composition of AA5083 can be found in Table 1. The three powder types, which are commonly employed in thermal spraying techniques, were co-deposited with powdered AA5083 on $6 \mathrm{~mm}$ 
thick AA5083 plates. Table 2 presents the composition of feedstock powders along with the associated particle size. Fig. 1 exhibits the distinctive morphologies of the respective powder particles.

Table 1. Chemical composition of AA5083 [47]

\begin{tabular}{ccccccccc}
\hline Element & $\mathrm{Mg}$ & $\mathrm{Si}$ & $\mathrm{Cr}$ & $\mathrm{Mn}$ & $\mathrm{Ti}$ & $\mathrm{Cu}$ & $\mathrm{Zn}$ & $\mathrm{Fe}$ \\
\hline $\mathrm{wt} \%$ & 4.9 & 0.4 & 0.25 & 1.0 & 0.15 & 0.1 & 0.25 & 0.4 \\
\hline
\end{tabular}

Table 2. Powder composition $[48,49]$

\begin{tabular}{llll}
\hline $\begin{array}{l}\text { Coating } \\
\text { Material }\end{array}$ & $\begin{array}{l}\text { Powder Identification } \\
\text { Code }\end{array}$ & Composition (wt.\%) & $\begin{array}{l}\text { Average Particle Size } \\
(\mu \mathrm{m})\end{array}$ \\
\hline WC-CoCr & Woka 3652 & $\mathrm{W}-10 \mathrm{Co}-5.5 \mathrm{C}-4.4 \mathrm{Cr}$ & 31.4 \\
$\mathrm{Cr}_{3} \mathrm{C}_{2}-\mathrm{NiCr}$ & Woka 7202 & $\mathrm{Cr}-20 \mathrm{Ni}-9.6 \mathrm{C}-0.1 \mathrm{Fe}$ & 27.3 \\
$\mathrm{Al}_{2} \mathrm{O}_{3}$ & $\mathrm{Al}-1110-\mathrm{HP}$ & $100 \mathrm{Al}_{2} \mathrm{O}_{3}$ & 75.8 \\
\hline
\end{tabular}

WC-CoCr (Fig. 1a) particles are spherical in shape and are comprised of nano-scale tungsten carbides held together by a binding cobalt matrix [49]. The addition of chromium decreases the susceptibility to corrosion as demonstrated by Toma et al. [50]. The $\mathrm{Cr}_{3} \mathrm{C}_{2}-\mathrm{NiCr}$ particles are comparable in size and morphology to WC-CoCr. However, the primary carbides within the $\mathrm{Cr}_{3} \mathrm{C}_{2}-\mathrm{NiCr}$ powder are larger than those contained within the WC-CoCr $[48,49]$. Chromium carbide acts as the hard constituent with the nickel-chromium binder retaining the carbides in the observed (Fig. 1b) spheroidal particle profile. Incorporation of chromium improves the corrosion resistance over tungsten-based powders whilst also increasing the ability to withstand greater in-service temperatures [48]. Both powders are commonly used to enhance the erosion or tribo-corrosion performance of components that are exposed to highly aggressive working environments. A number of existing studies [51,52] have demonstrated the improved erosion performance of materials that have been coated with WC-CoCr and $\mathrm{Cr}_{3} \mathrm{C}_{2}-\mathrm{NiCr}$ containing surfaces. As indicated in Table 2, $\mathrm{Al}_{2} \mathrm{O}_{3}$ particles are comparably larger in size and possess no metallic binder, with Fig. 1c illustrating the faceted shape of the oxides. The larger $\mathrm{Al}_{2} \mathrm{O}_{3}(75.8$ $\mu \mathrm{m})$ particles have been selected based on an improved deposition rate when compared with smaller $\mathrm{Al}_{2} \mathrm{O}_{3}$ particles. 


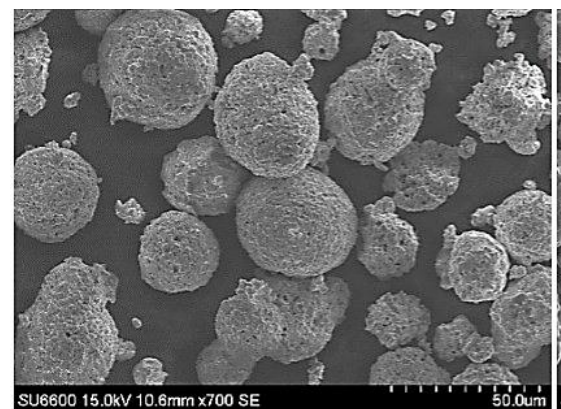

(a)

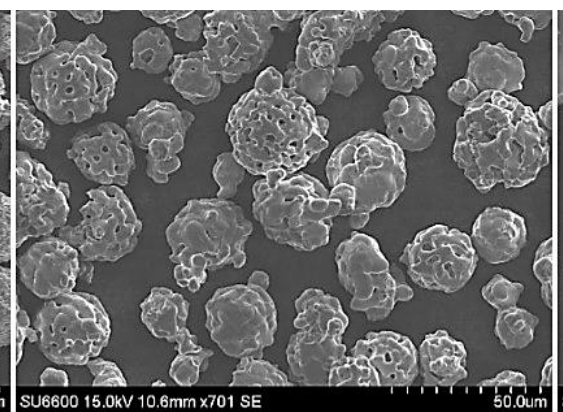

(b)

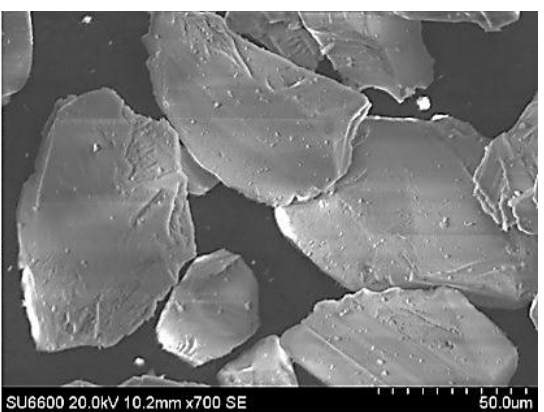

(c)

Fig. 1 Scanning electron micrographs of powder particles [x700]. a) WC-CoCr; b) $\mathrm{Cr}_{3} \mathrm{C}_{2}-\mathrm{NiCr}$; c) $\mathrm{Al}_{2} \mathrm{O}_{3}$

\subsection{Cold spray parameter development}

The aperture dimensions of the powder feeders were measured and the volumetric aperture ratio $(A R)$ between the two feeders calculated. The determined values were used to define the volumetric feed rate necessary to achieve the desired deposition ratio between reinforcing particle and aluminium binder. When referring to the co-deposited aluminium particles, the term "binder" is used for pre-deposition, with "matrix" used for post-deposition. The required rotational velocity of the feeder was calculated using Eq. 1, where $\omega_{r}$ is the rotational velocity of the powder feeder containing the reinforcing particles and $\omega_{m}$ is the velocity of the feeder containing the aluminium powder that will constitute the coating matrix.

$$
\omega_{r}=\omega_{m}\left(\frac{\text { Vol. } \%_{r}}{\text { Vol. } \%_{m}}\right) A R
$$

The spraying parameters identified as having the greatest influence on the quality of the deposited coating are gas temperature and gas pressure; the speed at which the nozzle traverses across the surface of the substrate and the nozzle standoff distance affect the quantity of material deposited [53]. An iterative approach was adopted to determine the optimal spraying conditions to achieve a dense, well adhered coating. The quantity of material deposited on the surface of the substrate was evaluated by measuring the coating thickness and mass gain following deposition on a series of test coupons. Table 3 presents the optimised spraying parameters.

Table 3. Optimised cold spray deposition parameters

\begin{tabular}{llll}
\hline $\begin{array}{l}\text { Gas } \\
\text { Pressure } \\
(\mathrm{MPa})\end{array}$ & $\begin{array}{l}\text { Gas Temperature } \\
\left({ }^{\circ} \mathrm{C}\right)\end{array}$ & $\begin{array}{l}\text { Scanning } \\
\text { Speed }(\mathrm{mm} / \mathrm{s})\end{array}$ & $\begin{array}{l}\text { Stand-off } \\
\text { Distance }(\mathrm{mm})\end{array}$ \\
\hline 3 & 500 & 100 & 50 \\
\hline
\end{tabular}




\subsection{Coating deposition}

Deposition of MMC coatings was carried out using a CGT GmbH Kinetiks 4000 cold spray system connected to two 4000 series powder feeders (Fig. 2).

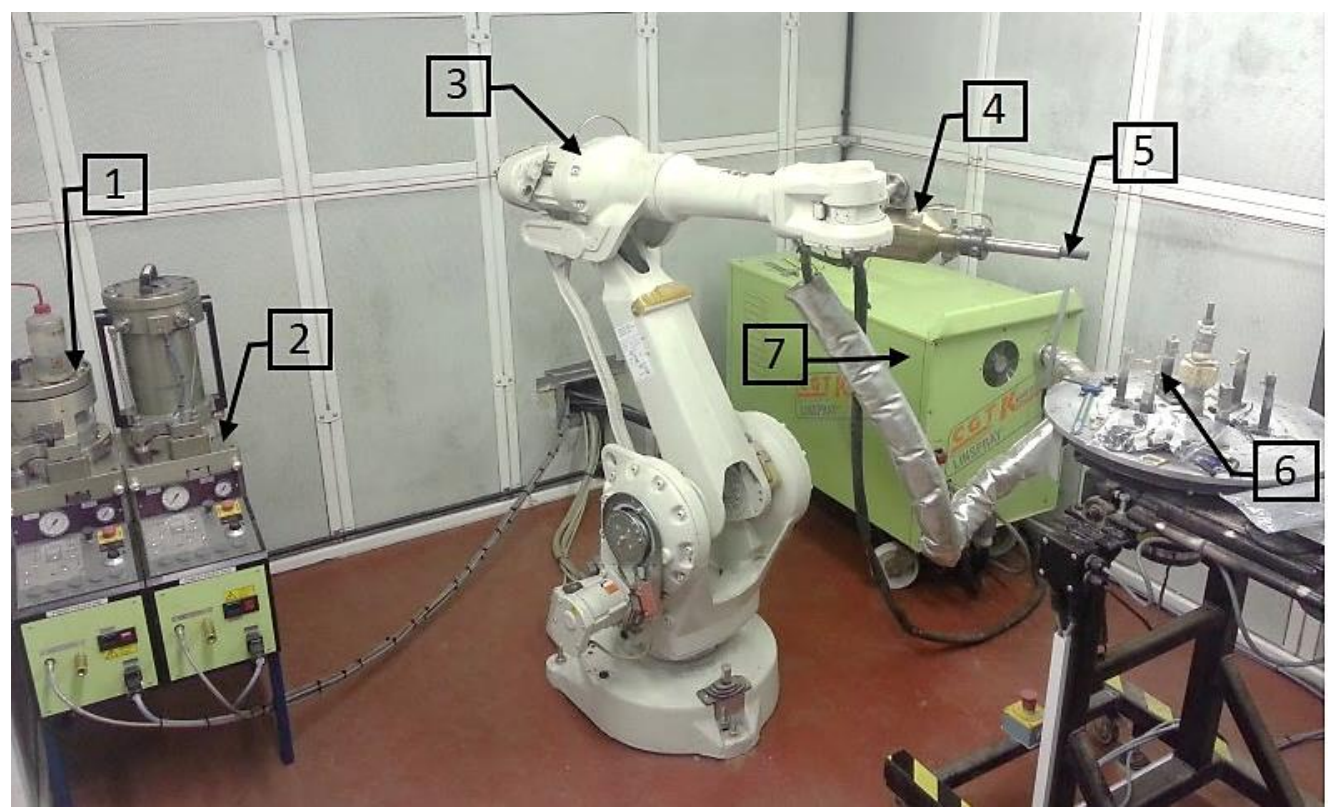

Fig. 2. Image of the cold spray setup. (1) Powder feeder 1; (2) Powder feeder 2; (3) Robotic arm; (4) Cold spray gun; (5) Cold spray nozzle; (6) Specimen stage; (7) Gas heater.

The spray system incorporated a conventional de-Laval nozzle to accelerate powder particles to the necessary velocity. The nozzle was attached to a 6-axis robotic arm to improve the repeatability of the coating deposition. Following the initial parameter development work, as outlined in section 2.2, the three reinforcement powders were co-deposited on the substrate material in the ratio $40 \%$ aluminium powder to $60 \%$ reinforcing particle (vol. $\%$ ). This ratio resulted in a coating thickness in the range $0.38-0.44 \mathrm{~mm}$ following the deposition of three layers ( 3 passes of the cold spray gun). The increased deposition rate of the $\mathrm{Cr}_{3} \mathrm{C}_{2}-\mathrm{NiCr}$ resulted in a coating thickness approximately $0.2 \mathrm{~mm}$ greater than that of $\mathrm{WC}-\mathrm{CoCr}$ and $\mathrm{Al}_{2} \mathrm{O}_{3}$. Consequently, only two passes of $\mathrm{Cr}_{3} \mathrm{C}_{2}-\mathrm{NiCr}$ were necessary to achieve a similar coating thickness. Further explanation as to the impact of the deposition efficiency on the MMC coatings is provided in section 3.1.1.

\subsection{Experimental procedure}

\subsubsection{Coating characterisation}

Specimens were cross-sectioned using a precision cutting wheel (Accutom 5) in order to minimise any damage to the coating layer and to limit the pull-out of reinforcement particles [54]. 
Standard metallographic techniques were employed to prepare the specimen surface to a $0.5 \mu \mathrm{m}$ finish using $\mathrm{SiC}$ grinding pads and a series of polishing stages. Optical micrographs of the MMC coatings were captured using an Olympus G51X light optical microscope and illustrate the distribution of the reinforcing particles within the aluminium matrix. The ratio of binder to reinforcing particles was measured using suitable image analysis software (ImageJ). High resolution images showing the distribution of carbides/oxides within the aluminium matrix were obtained using a Hitachi S-3700 series SEM. Energy dispersive spectroscopy (EDS) software (Oxford Instruments INCA) mapped the distribution of the constituent elements within the aluminium matrix thereby highlighting the dispersion of reinforcing particles throughout the MMC. The average hardness of the MMC was established by taking 10 micro-hardness measurements within the coating and calculating a mean average value. A Mitutoyo MVK-G1 micro-hardness tester with applied load of $100 \mathrm{gf}$ recorded the micro-hardness measurements. Assessment of reinforcement inter-particle spacing was carried out using a statistical analysis method developed by Khare et al. [55] that established the average free space length within a micrograph of the MMC coating on MATLAB.

\subsubsection{Solid-liquid impingement testing}

The erosion performance of the reinforced MMC coatings was evaluated using a closedloop solid liquid impingement test rig, as comparable systems have been used extensively by researches examining the erosion performance of materials within a flowing environment $[26,56,57]$. A schematic diagram of the test apparatus is depicted in Fig. 3. Test specimens were positioned directly under the jet nozzle and exposed to a slurry containing sand particles at $90^{\circ}$ angle of attack. The slurry used throughout the study was comprised of a $3.5 \mathrm{wt} . \% \mathrm{NaCl}$ solution containing FS9 grade angular silica sand with an average particle size of $0.355 \mathrm{~mm}$. The specimens were fully immersed in the slurry solution for the duration of the test. The system was flushed with fresh water following the conclusion of each test to remove any trace particulates and maintain consistent test conditions.

A closed-loop system offers the ability to modify the quantity of erosive particles within the slurry and accurately control the flow velocity. These variables have been shown in previous studies to have a measurable influence on the rate of material loss [58,59]. Table 4 presents the experimental parameters maintained throughout the test regime. 


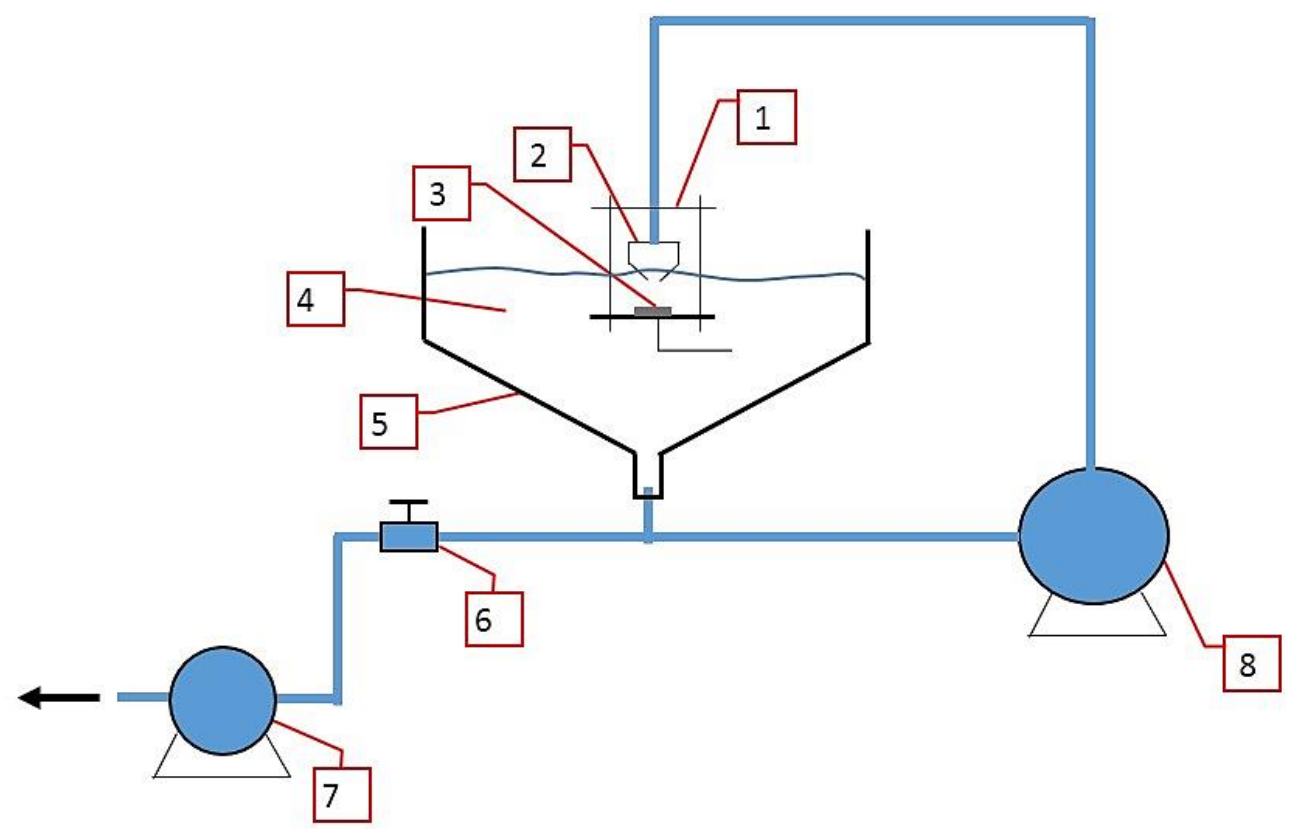

Fig 3. Schematic diagram of recirculating liquid impingement test rig (not to scale). (1) Sample holder; (2) Jet impingement nozzle; (3) Specimen; (4) Slurry solution; (5) Slurry tank; (6) Drainage valve; (7) Drainage pump; (8) Recirculating pump.

Table 4. Liquid impingement test parameters

\begin{tabular}{lllll}
\hline $\begin{array}{l}\text { Flow Velocity } \\
(\mathrm{m} / \mathrm{s})\end{array}$ & $\begin{array}{l}\text { Sand } \\
\text { Concentration } \\
(\mathrm{g} / \mathrm{l})\end{array}$ & $\begin{array}{l}\text { Standoff } \\
\text { Distance }(\mathrm{mm})\end{array}$ & $\begin{array}{l}\text { Test Time } \\
(\mathrm{min})\end{array}$ & $\begin{array}{l}\text { Sample } \\
\text { Diameter }(\mathrm{mm})\end{array}$ \\
\hline 22 & 0.4 & 20 & 20 & 20 \\
\hline
\end{tabular}

Prior to erosion testing, the specimens were abraded using 500-grit SiC paper to produce a uniform surface finish and weighed using a mass balance to an accuracy of $0.1 \mathrm{mg}$. The mass of each specimen was established pre- and post-testing to determine the total mass loss. Three test replicates for each MMC coating were weighed to provide an average mass loss value. Volume loss in the directly impinged and turbulent zones was evaluated using an Alicona (Infinite Focus G4) non-contact optical surface characterisation system. The system captures a 3D image of the scar region and plots data points on the surface. A reference plane is then added to represent to top surface of the specimen with the calculated volume beneath this plane signifying the volume loss. The directly impinged zone is classified as the area on the specimen surface that is located beneath the $3 \mathrm{~mm}$ aperture of the jet nozzle and corresponds to a surface area of $7.07 \mathrm{~mm}^{2}$. The material loss out with this region, identified as the turbulent zone, occurs as particles impinge and move outward from direct zone [60]. The volume of material removed from the turbulent zone is calculated by subtracting the volume loss in the directly impinged region 
from the total volume of the wear scar.

\section{Results and Discussion}

\subsection{MMC coating characterisation}

\subsubsection{Light optical microscopy}

Particle dispersal within an MMC has been the subject of many studies, due to the significant impact is has on the mechanical properties of the material [27,61]. As such, it is important to establish the dispersal of the reinforcing particles within the MMC and the effect of powder particle composition on this dispersal (Table 2). Fig. 4a exhibits a magnified cross section view of the WC-CoCr reinforced coating. The micrograph illustrates a dense coating with the minimal observed porosity attributed to pull-out during the metallographic preparation process [54]. This porosity was measured in accordance with ASTM E2109 - 01 [62] with the results inidicating an area percentage porosity less than $0.5 \%$. As mentioned in the standard, a value less than $0.5 \%$ should be considered zero when calculating the average area percentage of porosity. Therefore, the cold spray co-deposited coatings can be considered dense. This dense microstructures presented in Fig. 4 are a result of the significant deformation of co-deposited metallic binder particles as they impinge on the substrate surface [12,23], due to the high particle velocities generated by the cold spray system. An important observation from Fig. $4 \mathrm{a}$ is the agglomeration of WC-CoCr particles. This phenomenon has resulted in areas comprising high densities of reinforcement particles and contrasting regions that are void of any reinforcement material. Analysis of the MMC reports the coating to be comprised of approx. 56\% reinforcement particles and $44 \%$ binder (vol.\%). This value reflects the deposition ratio specified using Equation 1.

The $\mathrm{Cr}_{3} \mathrm{C}_{2}-\mathrm{NiCr}$ reinforced coating (Fig. 4b) reveals less agglomeration of particles when compared with the WC-CoCr MMC. Image analysis measured approx. 48\% cermet material within the $\mathrm{Cr}_{3} \mathrm{C}_{2}-\mathrm{NiCr}$ coating. The corresponding increase in binder (52\%) provides an explanation for the increase in coating thickness over WC-CoCr and $\mathrm{Al}_{2} \mathrm{O}_{3}$ reinforced coatings; equally, a study by Couto et al. [23] reported increased deposition efficiency with greater quantities of ductile binder. The reduction in particle agglomeration when compared with the WC-CoCr coating is attributed to the larger size of the $\mathrm{Cr}_{3} \mathrm{C}_{2}$-NiCr primary carbides. Specifically, the presence of larger carbides reduces the deformation that the $\mathrm{Cr}_{3} \mathrm{C}_{2}-\mathrm{NiCr}$ particles can undergo and as such reduces their ability to coalesce with the adjoining cermet particles. 


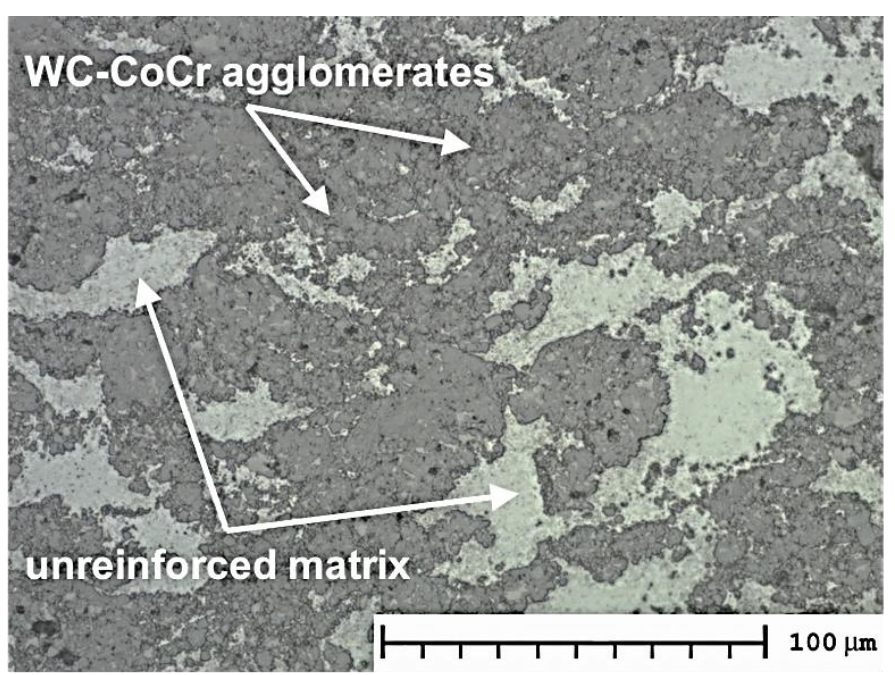

(a)

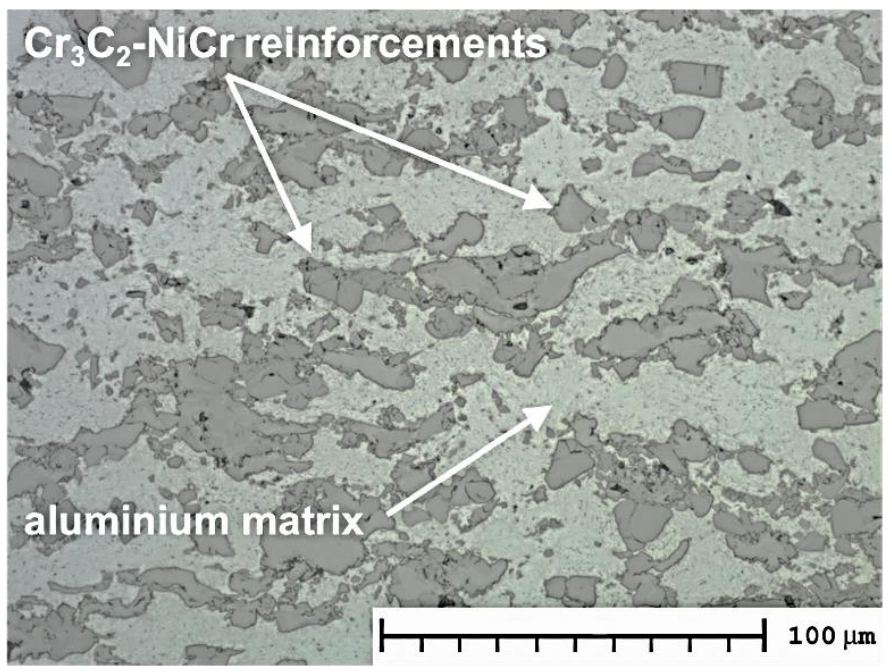

(b)

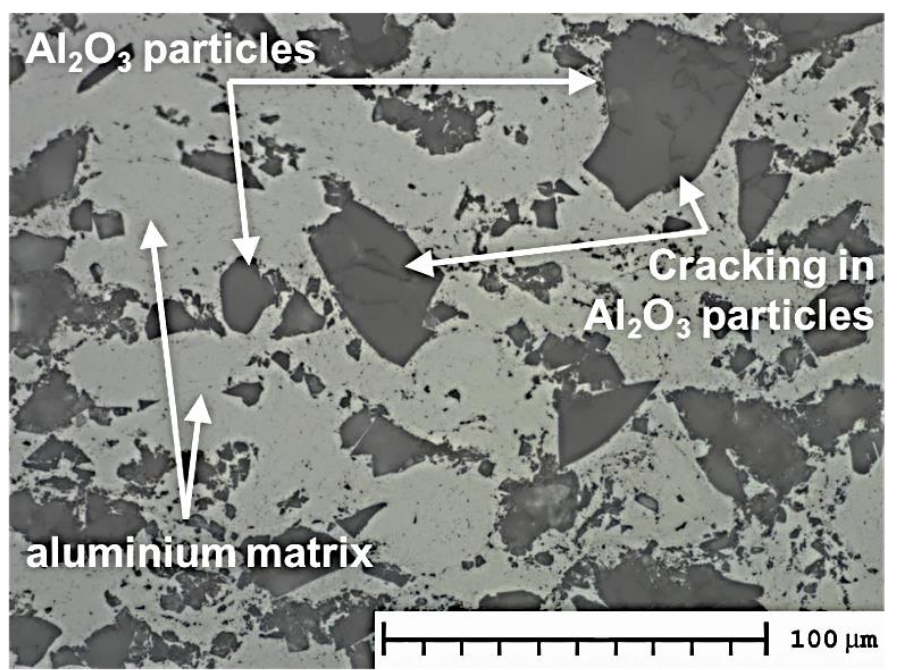

(c) 
Fig 4. Light optical micrographs showing the MMC coatings with the dark reinforcement particles dispersed throughout the light-shaded aluminium matrix [x500 unetched]. a) WC-CoCr, b) $\mathrm{Cr}_{3} \mathrm{C}_{2}-\mathrm{NiCr}, \mathrm{c}$ ) $\mathrm{Al}_{2} \mathrm{O}_{3}$

Examination of the $\mathrm{Al}_{2} \mathrm{O}_{3}$ coating (Fig. 4c) revealed that the MMC comprises approx. 60\% binder to $40 \%$ oxide particles. With the quantity of binder greater than that of the $\mathrm{Cr}_{3} \mathrm{C}_{2}-\mathrm{NiCr}$ reinforced coating it would be expected that deposition of the $\mathrm{Al}_{2} \mathrm{O}_{3} \mathrm{MMC}$ would result in the greatest coating thickness. This was not the case, however, one study by Spencer et al. [5] attributed this to particles rebounding from the surface due to a lack of deformation upon contact. This study [5] is in agreement with the recorded results considering that both WC-CoCr and $\mathrm{Cr}_{3} \mathrm{C}_{2}{ }^{-}$ $\mathrm{NiCr}$ contain inherent binder material in the form of cobalt and nickel, which as a result can plastically deform upon contact with the surface. Despite this, the $\mathrm{Al}_{2} \mathrm{O}_{3}$ reinforced coating comprises a homogenous distribution of particles. Fig. 4c does however depict a significant variation in the size of particles size within the aluminium matrix. This is attributed to the shattering of particles upon contact with the surface and is corroborated by evidence of cracking within the larger $\mathrm{Al}_{2} \mathrm{O}_{3}$ particles.

Based on the variation in the quantity of cermet material dispersed within the MMC matrix between the three reinforcing particles, it can be concluded that Equation 1 cannot be uniformly applied for every co-deposited powder material. The results indicate that the unique properties (morphology, density, shape) of the reinforcing particles impact the rate at which powder is supplied to the nozzle and must be accounted for when calculating the necessary rotational velocity of the powder feeder (section 2.2).

\subsubsection{Scanning electron microscopy}

EDS verified the presence of reinforcing particles within the MMC by determining the elemental composition of various regions within the coating. Furthermore, EDS elemental mapping evaluated the distribution of reinforcement particles within the aluminium matrix. The EDS map of the WC-CoCr reinforced coating is depicted in Fig. 5a. Fig. 5b is an optical micrograph of a corresponding region at an identical magnification to Fig. 5a. The locations of tungsten and cobalt align with the dark regions shown in the optical micrograph (Fig. 5b). Furthermore Fig. 6 also highlights the correlation between dark regions and reinforcing chromium/nickel elements in the $\mathrm{Cr}_{3} \mathrm{C}_{2}-\mathrm{NiCr}$ reinforced $\mathrm{MMC}$, thus it can be surmised that the dark regions in the optical micrographs depict the locations of reinforcement particles, as opposed to pull-out or contamination. 
Fig. 5a also illustrates the agglomeration of reinforcement particles within the matrix. Fiedler et al. [15] noted that micro-reinforcement mechanisms occur as a direct result of improved dispersion and reduced agglomerations (dispersion strengthening) [32]. A study by Slipenyuk et al. [27] concluded that increasing the average particle size led to improvements in the homogeneity of particle distribution in a $\mathrm{SiC}$ reinforced aluminium matrix [27]. However, increasing the average particle size has a deleterious effect on the mechanical properties of the MMC [27], therefore optimisation is necessary to achieve a balance between the desired properties. It was not possible to generate an EDS image map of the $\mathrm{Al}_{2} \mathrm{O}_{3}$ reinforced coating due to both matrix and reinforcing particle being comprised of aluminium.

High magnification SEM micrographs (Fig. 7a) demonstrate that the WC-CoCr particles have broken down (carbides no longer retained by the cobalt binder) following co-deposition. This is attributed to the deformation of particles upon contact with the substrate and the inability of the cobalt to retain the pre-deposition structure of the particles. Breakdown of feedstock particles aids the distribution of tungsten carbides throughout the MMC and is therefore deemed to be beneficial

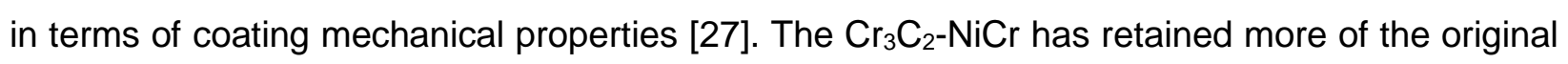
pre-deposition morphology with chromium carbides still surrounded by nickel binder (Fig. 7b). This indicates that the $\mathrm{Cr}_{3} \mathrm{C}_{2}$ - $\mathrm{NiCr}$ particles possess enhanced ductility due to the increased binder content (Table 2) which results in greater deformation prior to breakdown of the feedstock powder morphology.

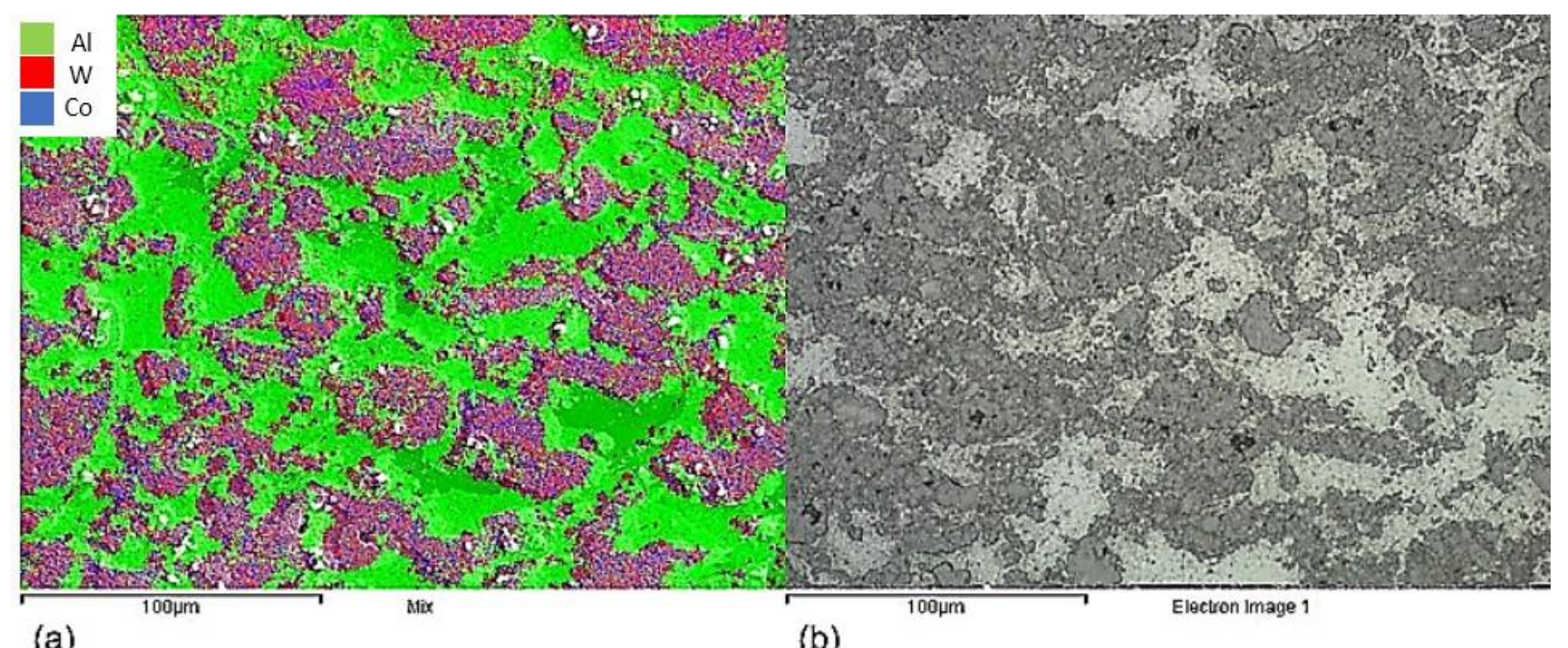

(a)

(b)

Fig. 5. a) EDS elemental map showing distribution of tungsten and cobalt within the aluminium matrix, b) light optical micrograph of a corresponding region in the WC-CoCr coating [x500, unetched]. 


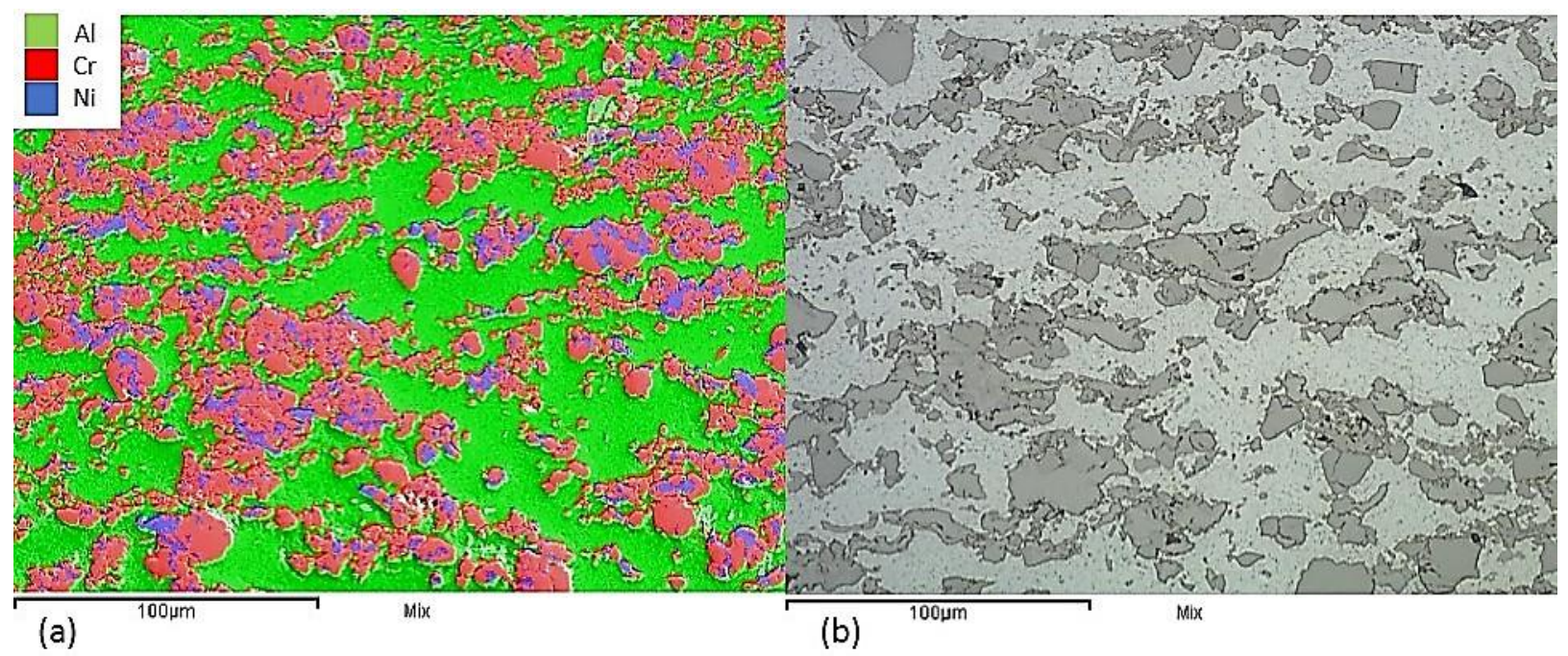

Fig. 6. a) EDS elemental map showing distribution of chromium and nickel within the aluminium matrix, b) light optical micrograph of a corresponding region in the $\mathrm{Cr}_{3} \mathrm{C}_{2}-\mathrm{NiCr}$ coating $[\mathrm{x} 500$, unetched].

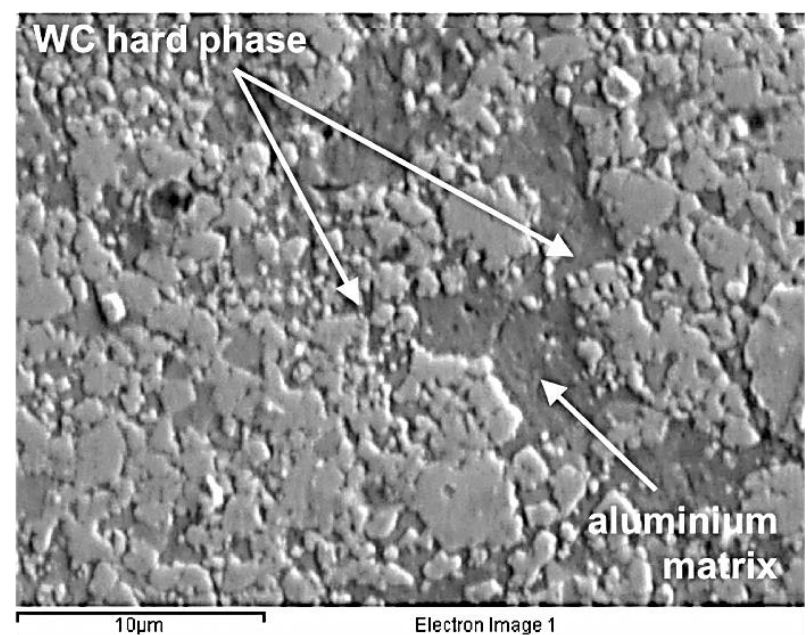

(a)

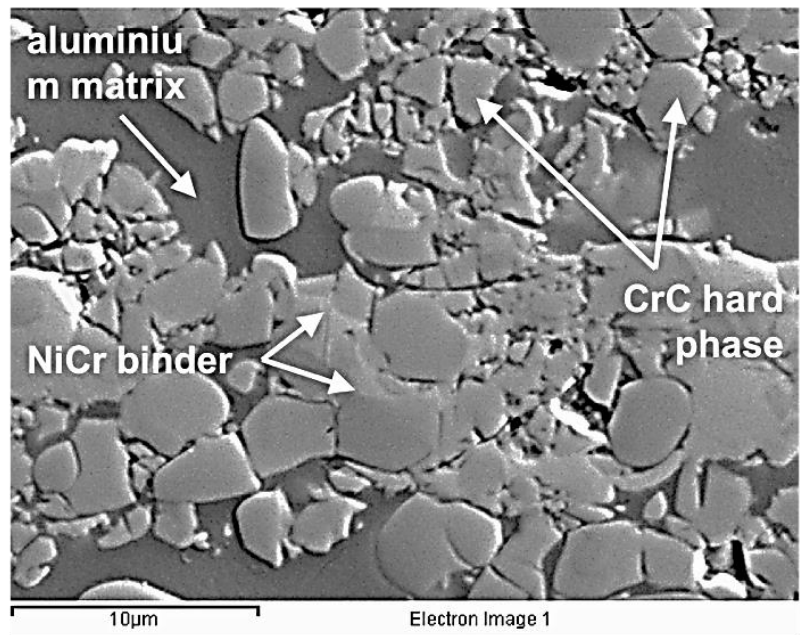

(b)

Fig 7. Scanning electron micrographs showing the dispersal of carbides within the aluminium matrix [x4000]. a) WC-CoCr, b) $\mathrm{Cr}_{3} \mathrm{C}_{2}-\mathrm{NiCr}$

\subsubsection{Micro-hardness}

To highlight the effect of the three types of reinforcing particles on the hardness of the MMCs, multiple micro-hardness measurements were taken within the coating layer with the average values presented in Fig. 8. The data shows the MMC with WC-CoCr reinforcing particles possess an average Vickers hardness of $389 \mathrm{HV}$. When compared with the unaltered AA5083, this value demonstrates a hardness increase of approx. $400 \%$. Despite this increase, the 
presented data contains a wide scatter of micro-hardness values for each coating type (Fig. 7). The scattering of results further highlights the agglomeration of particles within the MMC, with regions of high carbide content revealing high hardness values, and those comprising comparably lower quantities resulting in reduced micro-hardness.

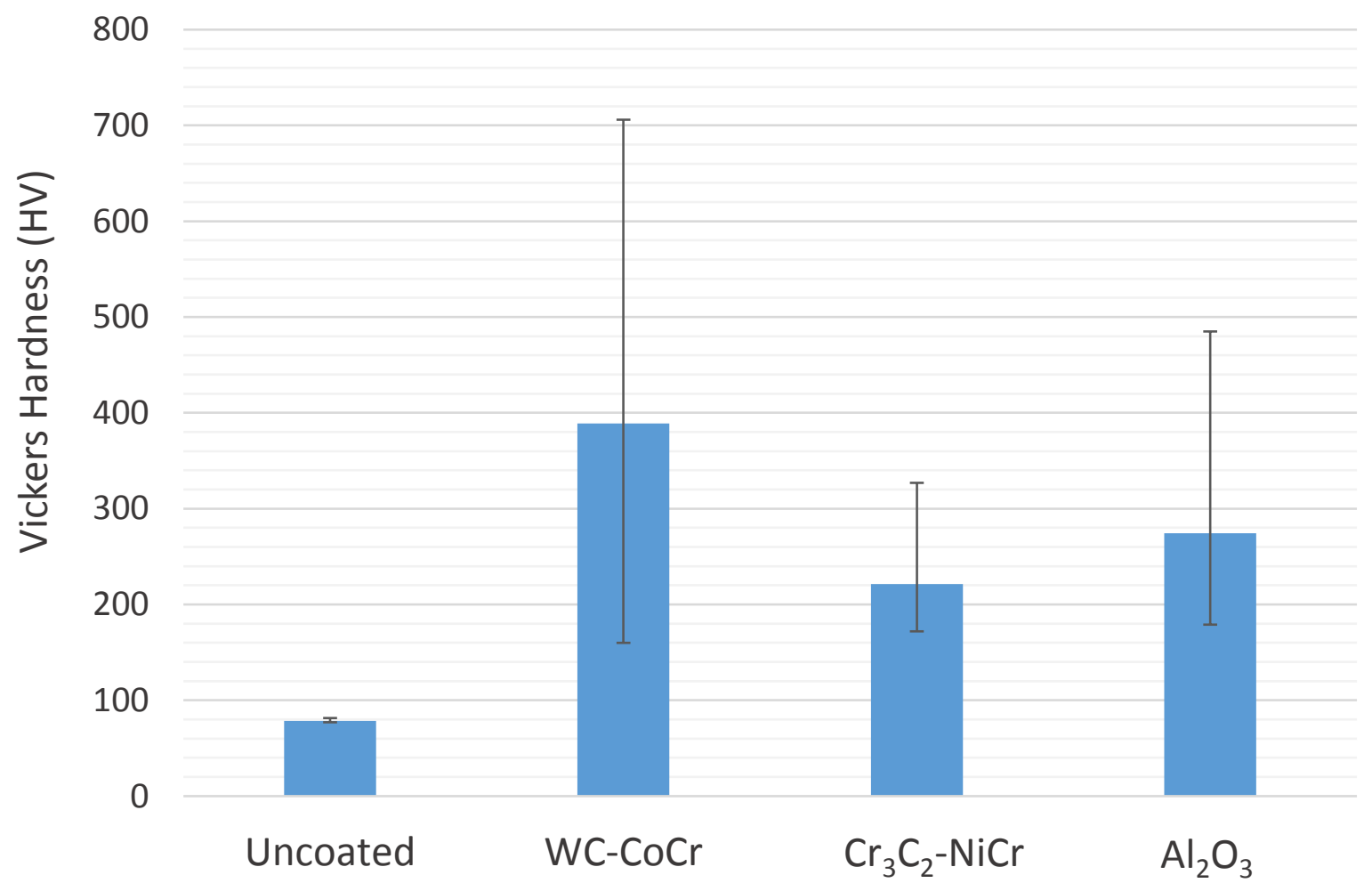

Fig. 8. Average micro-hardness of the co-deposited MMC coatings with the associated maximum and minimum recorded hardness values.

The average hardness of all three MMC coatings is greater than that of the as-received AA5083 material. This increase is attributed to the dispersion strengthening mechanism associated with particle reinforced MMCs. The presence of reinforcement particles restricts the movement of dislocations within the matrix and leads to improved hardness properties [32]. The level of dispersion strengthening is directly linked to the size and distribution of reinforcing particles, as demonstrated by Redsten et al. [39]. Work hardening and grain refinement from the plastic deformation of deposited binder particles has also contributed to the measured hardness increase of the MMC coatings [33]. Results from the hardness examination indicate that the presence of reinforcing particles increases the ability of the matrix to resist deformation under load [63], with the spread of micro-hardness values a direct consequence of the quantity of surrounding reinforcing particles limiting the plastic deformation of the MMC. Introduction of sub- 
micron reinforcement particles will further increase the hardness of the MMC as a result of dispersion strengthening [32].

\subsubsection{Inter-particle spacing}

The distribution of reinforcing particles has been shown by many authors $[18,64,65]$ to have a significant impact on the hardness and mechanical properties of the MMC. Moreover, the relationship between particle size and resulting distribution within the MMC has also been the subject of research $[27,29]$. The inter-particle spacing for the three coatings has been examined due to the reported influence of particle space on the yield strength of the MMC [64]. Khare and Barres's statistical method [55] measures the free space length which is defined as the width of the largest randomly placed square for which the mode average of intersecting particles is zero. This particular method was selected as it suitably accounts for the agglomeration of particles within the MMC [55]. Table 5 presents the measured inter-particle distance of the three coatings.

Table 5. Inter-particle distance

\begin{tabular}{llll}
\hline Coating & WC-CoCr & $\mathrm{Cr}_{3} \mathrm{C}_{2}-\mathrm{NiCr}$ & $\mathrm{Al}_{2} \mathrm{O}_{3}$ \\
\hline Inter-particle distance $(\mu \mathrm{m})$ & 11.5 & 15.3 & 13.1 \\
\hline
\end{tabular}

The results indicate that, despite the agglomeration of particles, the WC-CoCr reinforced MMC demonstrates the smallest inter-particle spacing. Such low inter-particle spacing is attributed to the greater quantity of reinforcing particles within the MMC (as discussed in section 3.1.1) and to the breakdown of particles as seen in Fig. 6a. Improved dispersion of fine reinforcing particles is directly related to an increase in dispersion strengthening as a result of dislocations in the aluminium matrix pinned by the reinforcement particles [32]. The size of the reinforcing particles has been shown in literature [27] to directly affect the distribution of particles within the MMC. Larger particles demonstrate improved dispersion within the matrix alloy [27], with fine particles showing a tendency to agglomerate as a result of inconsistent mixing during codeposition spraying. The larger size of $\mathrm{Al}_{2} \mathrm{O}_{3}$ particles has improved the homogeneity of particle dispersion within the aluminium matrix, however, as discussed by Slipenyuk et al. [27] is to the detriment of mechanical properties (hardness, yield and tensile strength).

\subsection{Solid-liquid impingement erosion study}

\subsubsection{Mass loss}

The influence of reinforcement particles on the total mass and volume loss sustained by the MMC coatings following exposure to 20 min solid liquid impingement testing is presented in Fig. 9. 


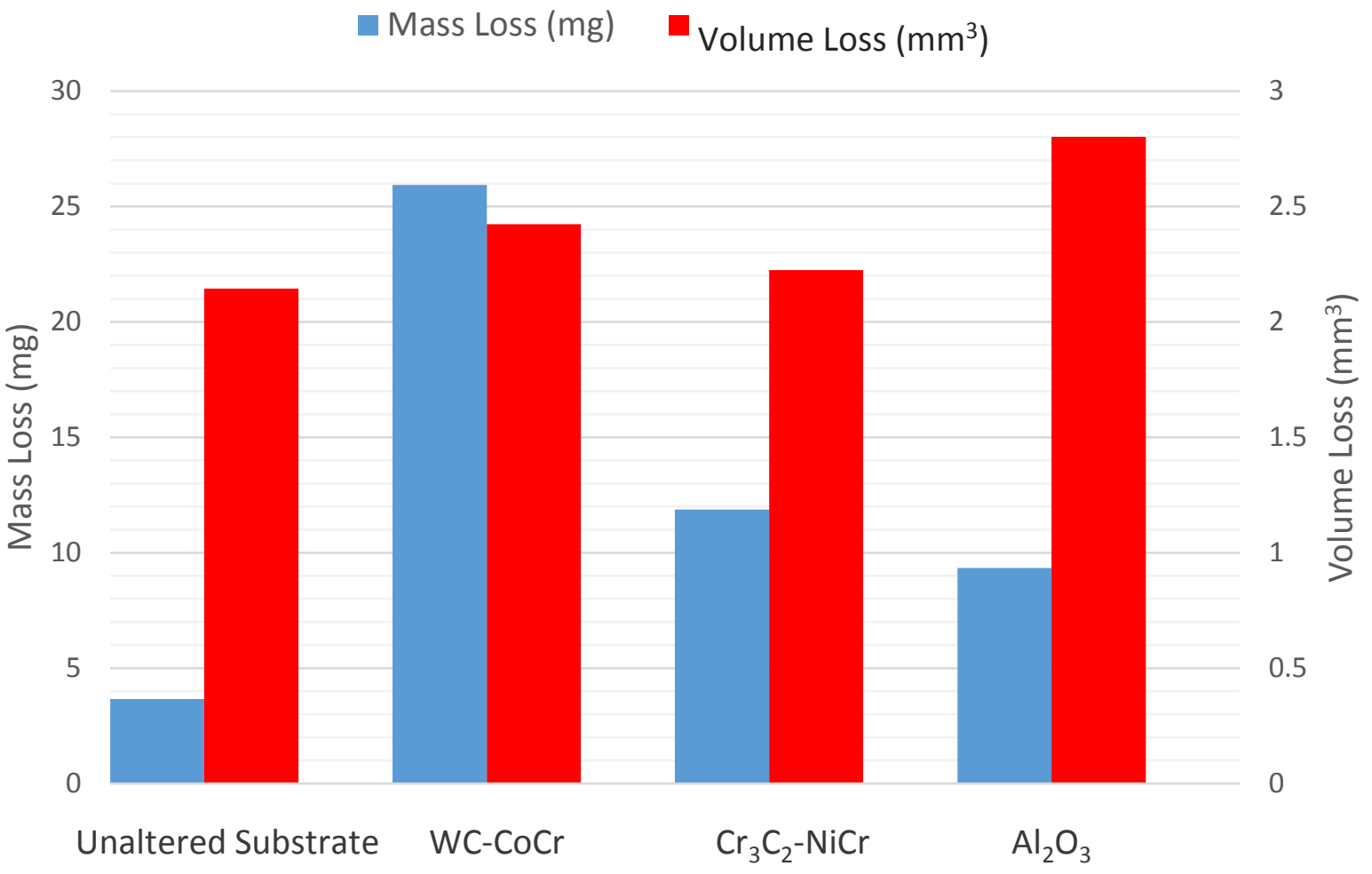

Fig. 9. Mass and volume loss following 20 minutes of exposure to the solid-liquid impingement testing.

The results display a significant variation in the level of mass loss experienced by each coating, with uncoated AA5083 material recording a significantly lower mass loss than the MMC coatings. The WC-CoCr reinforced specimen has resulted in the greatest mass loss out of the examined coatings with a value of more than double that of the next poorest performing MMC $\left(\mathrm{Cr}_{3} \mathrm{C}_{2}-\mathrm{NiCr}\right)$. The mass loss is reported for comparative analysis of the three reinforced MMCs exposed to consistent erosive conditions. However, due to the variation in density of the respective coatings, mass loss does not provide a suitable metric with which to present an assessment of MMCs composed of different reinforcing particles. As a result, it was necessary to establish the quantity of material removed by the impinging slurry as volume loss. The measured mass loss for the uncoated specimen would indicate that it has performed more than two times better than the poorest performing MMC coated specimen. However, examination of volume loss indicates that the uncoated material has performed similarly to the MMC specimens. Therefore, volume loss provides a more appropriate metric with which to comparatively assess the specimens as it takes into consideration the respective densities of each material. 


\subsubsection{Volume loss}

Volume loss in the directly impinged zone and the turbulent zone was characterised independently using the Alicona non-contact surface characterisation system and is presented in Fig. 10.

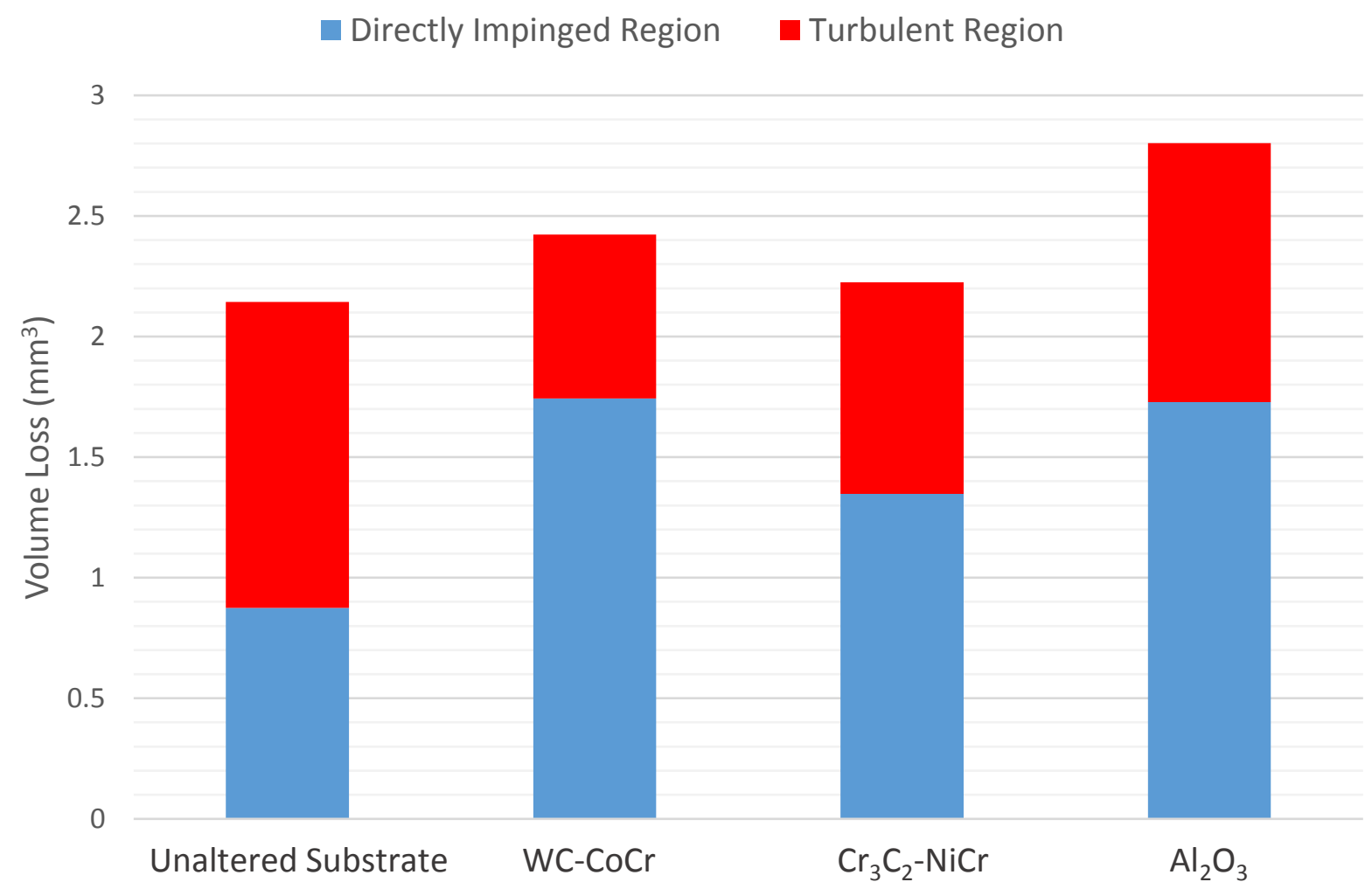

Fig. 10. Contribution of volume loss from the directly impinged and turbulent regions, to the total volume loss.

A number of conclusions can be drawn from the data presented in Fig. 10. The first is that the uncoated AA5083 has experienced greater volume loss in the turbulent zone than in the directly impinged zone. This outcome is attributed to the ductility of the as-received substrate material which typically exhibits greater erosion at acute angles of attack due to cutting and ploughing acting as the primary erosion mechanisms [66]. As the vol.\% of reinforcing particles is increased (section 3.1.1), the quantity of material removed from the turbulent zone decreases whilst the amount removed from the directly impinged zone increases. This shift demonstrates a change in the mechanisms causing material removal from ploughing of the ductile substrate to the fracture and removal of reinforcing particles [66]. The $\mathrm{Al}_{2} \mathrm{O}_{3}$ reinforced coating has resulted in the greatest volume loss within the wear scar with the recorded volume loss approximately $30 \%$ greater than that of the uncoated substrate. This increase in volume loss over the uncoated 
material is attributed to $\mathrm{Al}_{2} \mathrm{O}_{3}$ particles being plucked from the matrix and acting as a secondary erodent within the wear scar. The WC-CoCr reinforced MMC has performed poorly in comparison to the unaltered substrate and failed to provide increased erosion protection over the $\mathrm{Cr}_{3} \mathrm{C}_{2}-\mathrm{NiCr}$ reinforced coating. This is in contrast to many studies that state the substantial reduction in erosion rate with the addition on WC based cermets. While this outcome is contrary to the findings of many studies, the poor performance of the WC-CoCr reinforced MMC is a direct result of the highly aggressive environment in which specimens were tested. Furthermore, the agglomeration of WC-CoCr particles within the coating matrix has led to large agglomerates being plucked from the matrix due to a lack of supporting binder between the individual carbides.

\subsubsection{Wear scar analysis}

The reported mass and volume loss of the reinforced MMCs demonstrate that coatings fail to provide enhanced erosion protection over the as-received AA5083. SEM micrographs of the impinged region (Fig. 11) were examined to identify the cause of this unexpected outcome and evaluate the mechanisms resulting in this substantial level of material removal. The WC-CoCr reinforced coating (Fig. 11a) presents signs of damage to the aluminium matrix in the form of scoring and ploughing. This is consistent with ductile material removal and is frequently reported in the published literature $[43,66,67]$. Furthermore, Fig. 11a shows carbides that appear to protrude from the aluminium matrix. EDS analysis reveals low levels of aluminium in these regions thereby confirming a lack of supporting AA5083 required to retain the carbides within the aluminium matrix.

Figure $11 \mathrm{~b}$ highlights the presence of ductile scoring within the aluminium matrix. Ramesh et al. [68] reported similar findings following examination of HVOF sprayed WC-Co based coatings exposed to dry jet erosion. Particle agglomeration further enhances the rate of material removal as clusters of carbides are removed at the same time due to the extrusion of the surrounding matrix alloy [69]. Consequently, the quantity of eroded material is high with the presence of reinforcement particles offering no measurable improvement to the erosion performance of the MMC.

The $\mathrm{Cr}_{3} \mathrm{C}_{2}-\mathrm{NiCr}$ reinforced coating recorded the lowest volume loss when exposed to solid-liquid impingement conditions. Despite this, the resulting volume loss failed to offer any improvement over the unaltered substrate (Fig. 10). The enhanced erosion performance of this MMC over the WC-CoCr coating is a result of increased quantities of AA5083, which, as shown by the volume loss data, offers comparatively improved erosion resistance at a $90^{\circ}$ angle of attack [66]. Fig. 11c highlights the wear scar damage to the $\mathrm{Cr}_{3} \mathrm{C}_{2}-\mathrm{NiCr} \mathrm{MMC}$. The image reveals the removal of the AA5083 matrix and subsequent exposure of carbides. Hence this is recognised as 
the primary wear mechanism acting on the surface. The $\mathrm{Al}_{2} \mathrm{O}_{3}$ reinforced $M M C$ contains similar levels of matrix alloy to the $\mathrm{Cr}_{3} \mathrm{C}_{2}-\mathrm{NiCr}$ reinforced $\mathrm{MMC}$, however, demonstrates a comparably high volume loss. This outcome is related to the difference in reinforcement particle size between $\mathrm{Al}_{2} \mathrm{O}_{3}$ and $\mathrm{Cr}_{3} \mathrm{C}_{2}-\mathrm{NiCr}$. As shown in Table 2, the average size of $\mathrm{Al}_{2} \mathrm{O}_{3}$ particles is approx. $180 \%$ greater than that of $\mathrm{Cr}_{3} \mathrm{C}_{2}-\mathrm{NiCr}$ particles and far in excess of the maximum allowable particle size $(<1 \mu \mathrm{m})$ necessary to result in dispersion strengthening [32]. Micrographs of the $\mathrm{Al}_{2} \mathrm{O}_{3} \mathrm{MMC}$ (Fig. 4c) exhibit cracking of larger particles which results in an inability to contribute to load transfer strengthening, with the faceted particle shape resulting in lower ductility within the MMC [70]. Pullout of the large $\mathrm{Al}_{2} \mathrm{O}_{3}$ particles is highlighted in Fig. 11d.

Numerous authors [27,29,64,69-71] have explored the properties of distributed reinforcing particles in steel and aluminium alloys. For the majority of studies, the addition of reinforcing particles is found to improve the erosion resistance of MMC coatings. However, the results presented in this study, contradict these findings thus it is necessary to elucidate this phenomenon.

Ninham et al. [69] evaluated the erosion performance of reinforced carbon steel with varying quantities of WC cermet particles under dry jet erosion conditions. The authors discovered that, for WC content below 30\%, coatings exhibit a ductile degradation mechanism with the retaining matrix removed by the erodent and the carbides subsequently pulled from the matrix [69]. For WC content greater than $70 \%$, breakdown of the MMC occurs through the brittle fracture of the carbide particles [69]. The erosion resistance over uncoated substrate was improved for both of these respective WC quantities. However, the authors discovered that for MMCs alloys containing approx. $60 \%$ of reinforcing particles, the erosion rate was greater than MMCs containing high ( $>70 \%)$ and low $(<30 \%)$ quantities of WC. The authors attribute this observation to the displacement of the matrix alloy and subsequent removal of carbides. Considering that the quantity of reinforcing particles evaluated by Ninham et al. [69] is approximately equivalent to the quantity of reinforcing particle examined in the present study, the same mechanism is responsible for the poor erosion performance of MMC coatings recorded. By increasing the quantity of reinforcing particle to a value around $80 \%$ (vol.\%), the authors [69] discovered that the MMC demonstrates superior resistance to the erosive medium. Moreover, Singh et al. [18] discuss the importance of homogenous particle distribution on the mechanical properties of MMCs. Specifically, the authors reported improved tribological performance with the homogenous spatial distribution of reinforcing particles. Similar findings are reported by Machio et al. [72] under slurry erosive conditions. The authors [72] reported that a lower volume fraction of matrix and thus lower free space between adjacent reinforcement particles within the matrix resulted in improved 
erosion resistance. Based on this work, a reduction in the mean free path of reinforcement particles whilst increasing the vol.\% of reinforcement within the matrix would lead to improvement in the erosion performance of the MMC.
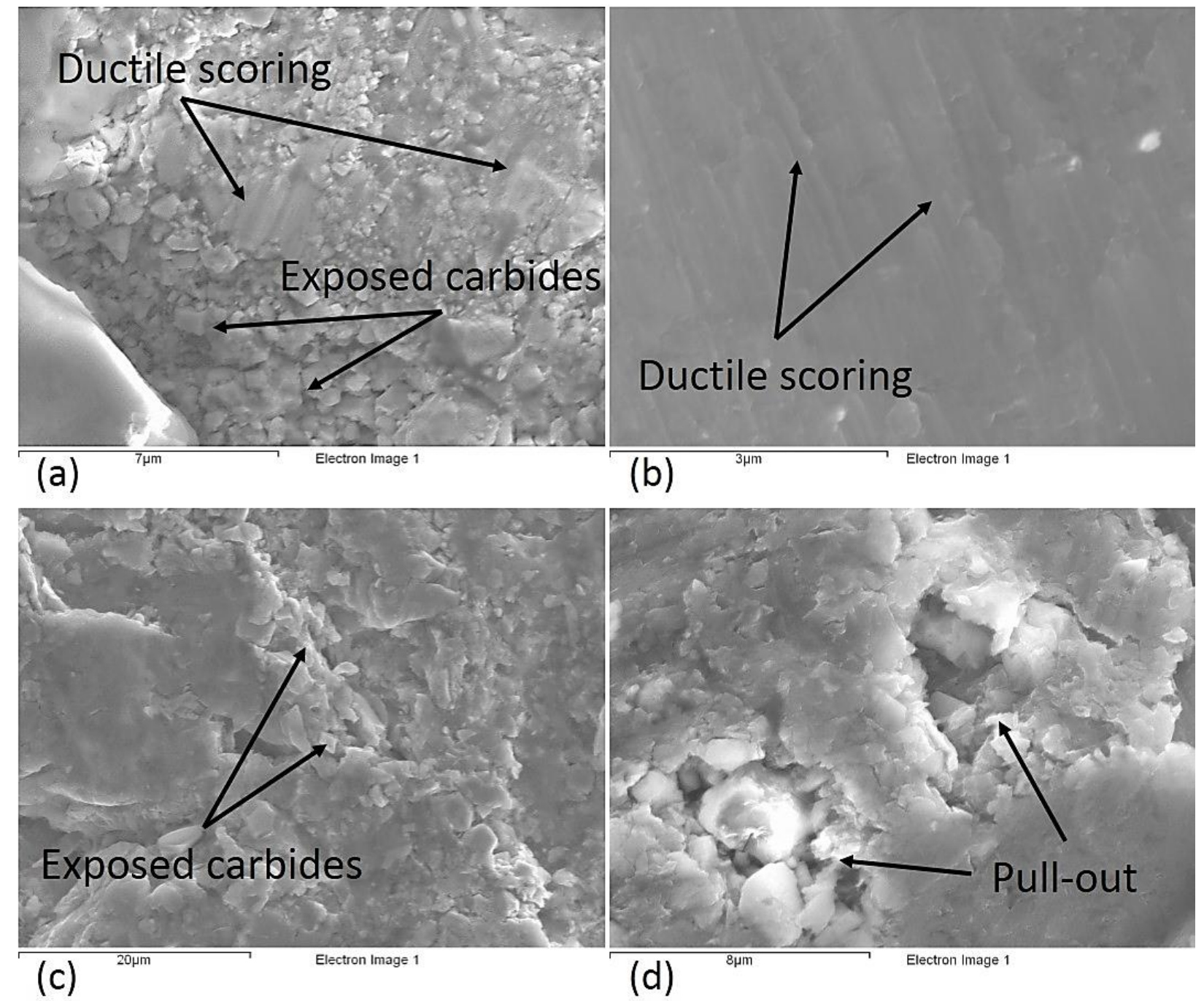

Fig. 11. Micrographs showing damage within the wear scar following solid-liquid impingement testing a) WC-CoCr [x8000], b) WC-CoCr [x20000], c) $\mathrm{Cr}_{3} \mathrm{C}_{2}-\mathrm{NiCr}$ [x2500], d) $\mathrm{Al}_{2} \mathrm{O}_{3}$ [x7000]

\section{Conclusions}

This study has successfully co-deposited a high ratio of WC-CoCr, $\mathrm{Cr}_{3} \mathrm{C}_{2}-\mathrm{NiCr}$ and $\mathrm{Al}_{2} \mathrm{O}_{3}$ reinforcing particles with a ductile binder via cold spray to produce MMC coatings on AA5083 plates. The development of suitable deposition parameters has been discussed in addition to the effects of particle morphology and distribution on the resulting erosion performance of the coatings. The effect of reinforcement particles on the manufactured coatings was characterised 
using a variety of metallographic characterisation techniques including light optical and scanning electron microscopy, image analysis and micro-hardness measurements. The erosion mechanisms responsible for the breakdown of coatings have been identified through assessment of the wear scars resulting from solid liquid impingement testing. The following conclusions can be drawn from this body of work.

- By co-depositing reinforcing particles with a ductile metallic binder, a thick, dense coating has been achieved. The build-up of coatings is attributed to the substantial deformation of the binding alloy that improves the contact area of adjacent particles.

- The findings of this study highlight that the specific properties (mass, density, morphology) of the feedstock material must be taken into consideration when co-depositing powder particles, to ensure the required ratio of binder to reinforcing particle is achieved.

- The hardness of deposited MMC coatings is highly dependent on the quantity of reinforcing particles in the surrounding region that limit the plastic deformation of the matrix alloy. The measured inter-particle spacing of the three coatings correlates well with the measured hardness values, with the highest hardness obtained in the WC-CoCr coating which also demonstrates the smallest inter-particle distance.

- Volumetric analysis of coatings following solid-liquid impingement testing has highlighted the poor performance of the MMC coatings under flowing erosion conditions. The findings of this study attribute the poor performance to agglomeration of reinforcing particles within the matrix. In the case of $\mathrm{Al}_{2} \mathrm{O}_{3}$, the use of large oxide particles fails to enhance the strength of the matrix through dispersion strengthening. Cracks present within the large oxide particles further reduce the strength of the MMC and enhance the level of erosion.

- The primary wear mechanisms operating within the MMC coatings have been evaluated through wear scar examination of the impinged regions. Findings highlight damage to the soft matrix alloy in the form of cutting and scoring which subsequently exposes carbide/oxide particles to the impinging slurry. The rate of material removal is further increased due to poor particle dispersal and the presence of large oxide particles (in the case of $\mathrm{Al}_{2} \mathrm{O}_{3}$ ).

- The incorporation of a secondary process to decrease average particle size and the average inter-particle spacing would lead to improved erosion performance based on the findings of this study and corresponding literature. 


\section{References}

[1] V.K. Champagne, The cold spray materials deposition process: fundamentals and applications, Woodhead Publishing, 2007.

[2] E.J.T. Pialago, C.W. Park, Cold spray deposition characteristics of mechanically alloyed Cu-CNT composite powders, Appl. Surf. Sci. 308 (2014) 63-74.

[3] J.M. Shockley, H.W. Strauss, R.R. Chromik, N. Brodusch, R. Gauvin, E. Irissou, et al., In situ tribometry of cold-sprayed Al-Al2O3 composite coatings, Surf. Coatings Technol. 215 (2013) 350-356.

[4] T. Peat, A. Galloway, T. Marrocco, N. lqbal, Microstructural Evaluation of Cold Spray Deposited WC with Subsequent Friction Stir Processing, Frict. Stir Weld. Process. VIII. (2015).

[5] K. Spencer, D.M. Fabijanic, M.X. Zhang, The use of Al-Al2O3 cold spray coatings to improve the surface properties of magnesium alloys, Surf. Coatings Technol. 204 (2009) 336-344.

[6] J.M. Shockley, S. Descartes, P. Vo, E. Irissou, R.R. Chromik, The influence of Al2O3 particle morphology on the coating formation and dry sliding wear behavior of cold sprayed Al-Al2O3 composites, Surf. Coatings Technol. 270 (2015) 324-333.

[7] M. Yandouzi, E. Sansoucy, L. Ajdelsztajn, B. Jodoin, WC-based cermet coatings produced by cold gas dynamic and pulsed gas dynamic spraying processes, Surf. Coatings Technol. 202 (2007) 382-390.

[8] H.S. Grewal, H. Singh, A. Agrawal, Understanding Liquid Impingement erosion behaviour of nickel-alumina based thermal spray coatings, Wear. 301 (2013) 424-433.

[9] E. Irissou, J.G. Legoux, B. Arsenault, C. Moreau, Investigation of Al-AI 203 cold spray coating formation and properties, J. Therm. Spray Technol. 16 (2007) 661-668.

[10] L. Singh, V. Chawla, J.S. Grewal, A review on detonation gun sprayed coatings, J. Miner. Mater. Charact. Eng. 11 (2012) 243-265.

[11] A. Papyrin, V. Kosarev, S. Klinkov, A. Alkhimov, V. Fomin, Cold Spray Technology, Elsevier, 2006.

[12] H. Assadi, F. Gärtner, T. Stoltenhoff, H. Kreye, Bonding mechanism in cold gas spraying, Acta Mater. 51 (2003) 4379-4394.

[13] W. Li, K. Yang, D. Zhang, X. Zhou, X. Guo, Interface behavior of particles upon impacting during cold spraying of Cu/Ni/Al mixture, Mater. Des. 95 (2016) 237-246.

[14] S. Grigoriev, A. Okunkova, A. Sova, P. Bertrand, I. Smurov, Cold spraying: From process fundamentals towards advanced applications, Surf. Coatings Technol. 268 (2015) 77-84.

[15] V. Luzin, K. Spencer, M.X. Zhang, Residual stress and thermo-mechanical properties of cold spray metal coatings, Acta Mater. 59 (2011) 1259-1270.

[16] G. Shayegan, H. Mahmoudi, R. Ghelichi, J. Villafuerte, J. Wang, M. Guagliano, et al., Residual stress induced by cold spray coating of magnesium AZ31B extrusion, Mater. Des. 60 (2014) 72-84.

[17] G. Shayegan, H. Mahmoudi, R. Ghelichi, J. Villafuerte, J. Wang, M. Guagliano, et al., Residual stress induced by cold spray coating of magnesium AZ31B extrusion, Mater. Des. 60 (2014) 72-84.

[18] J. Singh, A. Chauhan, Overview of wear performance of aluminium matrix composites reinforced with ceramic materials under the influence of controllable variables, Ceram. Int. 42 (2015) 56-81.

[19] M.K. Surappa, Aluminium matrix composites: Challenges and opportunities, Sadhana. 28 (2003) 319-334.

[20] R.S. Lima, J. Karthikeyan, C.M. Kay, J. Lindemann, C.C. Berndt, Microstructural characteristics of cold-sprayed nanostructured WC-Co coatings, Thin Solid Films. 416 (2002) 129-135. 
[21] F.L. Toma, L.M. Berger, C.C. Stahr, T. Naumann, S. Langner, Microstructures and functional properties of suspension-sprayed Al $2 \mathrm{O} 3$ and TiO 2 coatings: An overview, J. Therm. Spray Technol. 19 (2010) 262-274.

[22] D. Seo, M. Sayar, K. Ogawa, SiO 2 and MoSi 2 formation on Inconel 625 surface via SiC coating deposited by cold spray, Surf. Coatings Technol. 206 (2012) 2851-2858.

[23] M. Couto, S. Dosta, M. Torrell, J. Fernández, J.M. Guilemany, Cold spray deposition of WC-17 and 12Co cermets onto aluminum, Surf. Coatings Technol. 235 (2013) 54-61.

[24] R.S. Lima, B.R. Marple, Thermal spray coatings engineered from nanostructured ceramic agglomerated powders for structural, thermal barrier and biomedical applications: A review, J. Therm. Spray Technol. 16 (2007) 40-63.

[25] S. Li, K. Kondoh, H. Imai, B. Chen, L. Jia, J. Umeda, et al., Strengthening behavior of in situ -synthesized ( $\mathrm{TiC}-\mathrm{TiB}$ )/ Ti composites by powder metallurgy and hot extrusion, Jmade. 95 (2016) 127-132.

[26] A. Neville, F. Reza, S. Chiovelli, T. Revega, Erosion-corrosion behaviour of WC-based MMCs in liquid-solid slurries, in: Wear, 2005: pp. 181-195.

[27] A. Slipenyuk, V. Kuprin, Y. Milman, J.E. Spowart, D.B. Miracle, The effect of matrix to reinforcement particle size ratio (PSR) on the microstructure and mechanical properties of a P/M processed AICuMn/SiCp MMC, Mater. Sci. Eng. A. 381 (2004) 165-170.

[28] K.J. Hodder, H. Izadi, A.G. McDonald, A.P. Gerlich, Fabrication of aluminum-alumina metal matrix composites via cold gas dynamic spraying at low pressure followed by friction stir processing, Mater. Sci. Eng. A. 556 (2012) 114-121.

[29] H. Gül, F. Kili, M. Uysal, S. Aslan, A. Alp, H. Akbulut, Effect of particle concentration on the structure and tribological properties of submicron particle $\mathrm{SiC}$ reinforced Ni metal matrix composite (MMC) coatings produced by electrodeposition, Appl. Surf. Sci. 258 (2012) 4260-4267.

[30] N.K. Babu, K. Kallip, M. Leparoux, K.A. AlOgab, X. Maeder, Y.A.R. Dasilva, Influence of microstructure and strengthening mechanism of AlMg5-Al2O3 nanocomposites prepared via spark plasma sintering, Mater. Des. 95 (2016) 534-544.

[31] S.K. Mishra, S. Biswas, A. Satapathy, A study on processing, characterization and erosion wear behavior of silicon carbide particle filled ZA-27 metal matrix composites, Mater. Des. 55 (2014) 958-965.

[32] Z. Zhang, D.L. Chen, Contribution of Orowan strengthening effect in particulatereinforced metal matrix nanocomposites, Mater. Sci. Eng. A. 483-484 (2008) 148-152.

[33] X.T. Luo, G.J. Yang, C.J. Li, Multiple strengthening mechanisms of cold-sprayed cBNp/NiCrAl composite coating, Surf. Coatings Technol. 205 (2011) 4808-4813.

[34] H.J. Fecht, Nanostructure formation by mechanical attrition, Nanostructured Mater. 6 (1995) 33-42.

[35] C. Borchers, F. Gärtner, T. Stoltenhoff, H. Assadi, H. Kreye, Microstructural and macroscopic properties of cold sprayed copper coatings, J. Appl. Phys. 93 (2003) 1006410070.

[36] A.C. Hall, L.N. Brewer, T.J. Roemer, Preparation of aluminum coatings containing homogenous nanocrystalline microstructures using the cold spray process, J. Therm. Spray Technol. 17 (2008) 352-359.

[37] C.J. Li, W.Y. Li, Y.Y. Wang, Formation of metastable phases in cold-sprayed soft metallic deposit, Surf. Coatings Technol. 198 (2005) 469-473.

[38] K. Kim, M. Watanabe, J. Kawakita, S. Kuroda, Grain refinement in a single titanium powder particle impacted at high velocity, Scr. Mater. 59 (2008) 768-771.

[39] A.M. Redsten, E.M. Klier, A.M. Brown, D.C. Dunand, Mechanical properties and microstructure of cast oxide-dispersion-strengthened aluminum, Mater. Sci. Eng. A. 201 (1995) 88-102.

[40] D.A. Stewart, P.H. Shipway, D.G. McCartney, Abrasive wear behaviour of conventional 
and nanocomposite HVOF-sprayed WC-Co coatings, Wear. 225-229 (1999) 789-798.

[41] P.H. Shipway, D.G. McCartney, T. Sudaprasert, Sliding wear behaviour of conventional and nanostructured HVOF sprayed WC-Co coatings, Wear. 259 (2005) 820-827.

[42] B.W. Chua, L. Lu, M.O. Lai, Influence of SiC particles on mechanical properties of Mg based composite, Compos. Struct. 47 (1999) 595-601.

[43] Q. Fang, P. Sidky, M.. Hocking, Erosive wear behaviour of aluminium based composites, Mater. Des. 18 (1997) 389-393.

[44] L. Liu, J. Xu, A study of the erosion-corrosion behavior of nano-Cr2O 3 particles reinforced Ni-based composite alloying layer in aqueous slurry environment, Vacuum. 85 (2011) 687-700.

[45] S. Toros, F. Ozturk, I. Kacar, Review of warm forming of aluminum-magnesium alloys, J. Mater. Process. Technol. 207 (2008) 1-12.

[46] K.U. Kainer, Metal matrix composites: custom-made materials for automotive ans aerospace engineering, Wiley-vch, 2006.

[47] The Aluminum Association Inc., International Alloy Designations and Chemical Composition Limits for Wrought Aluminum and Wrought Aluminum Alloys, Alum. Assoc. Arlington, Virginia. (2006) 28.

[48] Oerlikon Metco, Material Product Data Sheet Chromium Carbide - Nickel Chromium Powder Blends, 2 (2014) 2-7.

[49] Oerlikon Metco, Material Product Data Sheet Tungsten Carbide - $10 \%$ Cobalt $4 \%$ Chromium Powders, (2015) 1-7.

[50] D.U. Toma, W. Brandl, G. Marginean, Wear and corrosion behaviour of thermally sprayed cermet coatings, Surf. Coat. Technol. (2001) 149-158.

[51] L. Thakur, N. Arora, R. Jayaganthan, R. Sood, An investigation on erosion behavior of HVOF sprayed WC-CoCr coatings, Appl. Surf. Sci. 258 (2011) 1225-1234.

[52] S. Hong, Y. Wu, Q. Wang, G. Ying, G. Li, W. Gao, et al., Microstructure and cavitation-silt erosion behavior of high-velocity oxygen-fuel (HVOF) sprayed Cr3C2-NiCr coating, Surf. Coatings Technol. 225 (2013) 85-91.

[53] H. Assadi, T. Schmidt, H. Richter, J.O. Kliemann, K. Binder, F. G??rtner, et al., On parameter selection in cold spraying, J. Therm. Spray Technol. 20 (2011) 1161-1176.

[54] Struers, Metallographic preparation of thermal spray coatings, 2014.

[55] H.S. Khare, D.L. Burris, A quantitative method for measuring nanocomposite dispersion, Polymer (Guildf). 51 (2010) 719-729.

[56] J. Yao, F. Zhou, Y. Zhao, H. Yin, N. Li, Investigation of erosion of stainless steel by twophase jet impingement, Appl. Therm. Eng. (2014) 1-10.

[57] A. Neville, T. Hodgkiess, J.T. Dallas, A study of the erosion-corrosion behaviour of engineering steels for marine pumping applications, Wear. 186-187 (1995) 497-507.

[58] X. Jiang, Y.G. Zheng, W. Ke, Effect of flow velocity and entrained sand on inhibition performances of two inhibitors for $\mathrm{CO} 2$ corrosion of $\mathrm{N} 80$ steel in $3 \% \mathrm{NaCl}$ solution, Corros. Sci. 47 (2005) 2636-2658.

[59] N. Andrews, L. Giourntas, A.M. Galloway, A. Pearson, Effect of impact angle on the slurry erosion-corrosion of Stellite 6 and SS316, Wear. 320 (2014) 143-151.

[60] L. Giourntas, T. Hodgkiess, A.M. Galloway, Comparative study of erosion-corrosion performance on a range of stainless steels, Wear. 332-333 (2015) 1051-1058.

[61] S. V. Kamat, J.P. Hirth, R. Mehrabian, Mechanical properties of particulate-reinforced aluminum-matrix composites, Acta Metall. 37 (1989) 2395-2402.

[62] International ASTM Standard, ASTM E2109 - 01 (2014): Standard Test Methods for Determining Area Percentage Porosity in Thermal Sprayed Coatings, (2006) 1-8.

[63] A. Pramanik, L.C. Zhang, J.A. Arsecularatne, Deformation mechanisms of MMCs under indentation, Compos. Sci. Technol. 68 (2008) 1304-1312.

[64] P.A. Karnezis, G. Durrant, B. Cantor, Characterization of Reinforcement Distribution in 
Cast Al-Alloy/SiCp Composites, Mater. Charact. 40 (1998) 97-109.

[65] S.B. Prabu, L. Karunamoorthy, S. Kathiresan, B. Mohan, Influence of stirring speed and stirring time on distribution of particles in cast metal matrix composite, J. Mater. Process. Technol. 171 (2006) 268-273.

[66] D. Aquaro, E. Fontani, Erosion of ductile and brittle materials, Meccanica. 36 (2001) 651661.

[67] W. Wu, K.C. Goretta, J.L. Routbort, Erosion of 2014 Al reinforced with SiC or Al2O3 particles, Mater. Sci. Eng. A. 151 (1992) 85-95.

[68] M.R. Ramesh, S. Prakash, S.K. Nath, P.K. Sapra, B. Venkataraman, Solid particle erosion of HVOF sprayed WC-Co/NiCrFeSiB coatings, Wear. 269 (2010) 197-205.

[69] A.J. Ninham, A. V Levy, The erosion of carbide-metal composites, Wear. 121 (1988) 347-361.

[70] N. Chawla, Y. Shen, Mechanical Behavior of Particle Reinforced Metal Matrix Composites, Adv. Eng. Mater. 3 (2001) 357-370.

[71] R. Miranda, Surface reinforcements of light alloys, Woodhead Publishing Limited, 2014.

[72] C.N. Machio, G. Akdogan, M.J. Witcomb, S. Luyckx, Performance of WC-VC-Co thermal spray coatings in abrasion and slurry erosion tests, Wear. 258 (2005) 434-442. 